\title{
Virtual learning system usage in Higher Education-A study at two South African institutions
}

\author{
Indira Padayachee ${ }^{a}$, Alta van der Merwe ${ }^{b}$, Paula Kotzéc, b \\ a School of Management, Information Technology \& Governance, University of KwaZulu-Natal, Durban, South \\ Africa \\ ${ }^{b}$ Department of Informatics, University of Pretoria, South Africa \\ ${ }^{c}$ CSIR Meraka Institute, Pretoria, South Africa
}

\begin{abstract}
In higher education institutions various VLSs have been formally adopted to support online teaching and learning. However, there has been little research on patterns of VLS use among educators. The purpose of the research was to provide a descriptive analysis of VLS feature usage, and associated challenges at two South African higher education institutions. A case study research strategy was adopted, combining qualitative and quantitative approaches to data collection and analysis. Survey findings revealed four clusters of VLS feature usage, namely, communication, management, content and pedagogic. Analysis showed that the 'content cluster' was used more than the other clusters. The average usage of the 'pedagogic cluster' for Durban University of Technology (DUT) was significantly greater than that of University of KwaZulu-Natal (UKZN), which tentatively indicates that staff development seems to be an important aspect of VLS usage. There was no significant difference in the usage of the 'communication' and 'management' clusters between the two institutions, DUT and UKZN. The study contributes to the body of system utilisation research by confirming an uneven pattern of VLS feature usage among educators, whilst providing fresh insights into the challenges associated with the usage of two different VLSs in two different universities.
\end{abstract}

Keywords: Virtual learning environment usage, course management systems, learning management systems, e-learning, tools for online teaching and learning, virtual learning environment features

Categories: K.3.1 [Computers and Education]: Computer uses in education.

\section{Email:}

Indira Padayachee padayacheei@ukzn.ac.za (CORRESPONDING), Alta van der Merwe alta.vdm@up.ac.za,

Paula Kotzé paula.kotze@meraka.org.za

\section{Article history:}

Received: 17 May 2015

Accepted: 8 Dec 2015

Available online: 10 Dec 2015

\section{INTRODUCTION}

Virtual learning systems (VLSs) refer to a class of software that is known by a number of names including course management systems (CMSs), learning management systems (LMSs), virtual learning environments (VLEs), online learning platforms, and e-learning applications. VLSs are

Padayachee, I., van der Merwe, A., and Kotzé, P. (2015). Virtual learning system usage in Higher Education-A study at two South African institutions. South African Computer Journal 57, 32-57. http://dx.doi.org/10.18489/sacj.v0i57.324 Copyright (C) the author(s); published under a Creative Commons NonCommercial 4.0 License (CC BY-NC 4.0). $S A C J$ is a publication of the South African Institute of Computer Scientists and Information Technologists. ISSN 1015-7999 (print) ISSN 2313-7835 (online). 
playing an important role in the academic enterprise of teaching and learning, similar to the role occupied by enterprise resource planning (ERP) systems in the area of administration. A VLS contains aspects of administration, but also deals directly with the core aspects of teaching, such as learning objects, class exercises, quizzes and tests, and integrates tools for real-time chats and asynchronous bulletin board communication. Just as an administrative ERP system would relate to various aspects of higher education, such as finance and human resources, the VLS is poised to make an impact on all aspects of teaching and learning and student-teacher interactions (Meerts, 2003).

Currently, VLSs offer educators a variety of tools and features, which provide more opportunities for innovative educational application and increased use of the system than traditional lecturebased teaching methods. According to Yueh and Hsu (2008), studies focusing on the actual use of VLSs reveal that some functions are used more often than others. The findings of an online survey, conducted in 2007, on VLS usage by academic staff at the University of KwaZulu-Natal (UKZN), showed that a large part of the usage involved content distribution, in contrast to learning, communication, testing and grading activities (Jackson, n.d.). In another study, Mlitwa (2007) reported that the learning landscape in higher education institutions in the Western Cape showed high adoption levels of VLSs against uneven usage patterns. Mlitwa and Van Belle (2011) reported that e-learning was perceived as a content repository and administration tool for the submission and management of assignments, as well as facilitating easy communication, rather than as a system for teaching and learning.

Welle-Strand \& Thune [49] report that while there is a lot of information about e-learning solutions, knowledge of actual use is still limited in terms of what types of technology are used and how they are used. This view is supported by Britain and Liber (2004) who stated that there is little information available with regard to the way that VLSs are being used within institutions to support teaching and learning functions.

The gap between the VLS features available and those actually used for online teaching and learning are explored in the research presented in this paper. The problem focuses on the lack of widespread usage, in institutions of higher education, of the functions/features of VLSs to support teaching and learning activities and the management of courses. The research focuses specifically on (1) the extent and frequency of VLS feature usage by educators, (2) the clusters of VLS features used by educators, and (3) the issues associated with VLS usage by educators. The research involved two higher education institutions in South Africa.

The theoretical background to the research problem is presented in Section 2 covering virtual learning system features, usage in higher education, and associated issues. Section 3 presents the research methodology followed by Section 4, which presents the findings and analysis of the research undertaken. A summative discussion is provided in Section 5 , followed by the conclusion in Section 6 .

\section{THEORETICAL BACKGROUND}

Virtual learning systems allow higher education institutions to stay abreast of latest educational technologies, to be competitive in the higher education domain and to afford their stakeholders new innovative ways of teaching and learning. Educational technology is advancing at a vast pace and 
institutions have to keep abreast or fall behind.

Technology plays the role of enabler of learning and of creating connections (Siemens, n.d.). According to Blinco, Mason, McLean and Wilson (2004), the choice of options that facilitate learning is increasing as a result of the availability of a wide range of information and communication technologies. E-learning currently encompasses an increasingly wide scope of applications and activity, including, portals, m-learning, activity-based learning applications, and e-portfolio software (Blinco et al., 2004).

Virtual learning systems are a newer breed of educational technology comprising tools for teaching and learning designed to improve the students' learning experiences (Cavus \& Momani, 2009). The influence of Web 2.0 on VLSs is supported by the development of wiki and blog plug-ins for Blackboard (2006) and Moodle (Cole \& Foster, 2007). The connection between VLSs and Web 2.0 can also be seen with the advent of tools by which VLS users can publish micro content to the open web. An example of such services is "Blackboard Scholar.com" (Alexander, 2008). Current VLSs do not incorporate personalisation of learning which emphasises key aspects such as learning based on diverse learner needs, flexibility, a choice of learning options, lifelong learning, combining formal and informal learning, and allowing the learner to organise his/her own learning (Kompen, Edirisingha \& Mobbs, 2010). Lang and Pirani (2014) predict four future trends for VLSs, namely system customisation/personalisation; data and analytics; and system integration and mobility.

Other educational tools that followed in the wake of social networks and the development of immersive virtual learning environments are social networking applications such as Facebook (n.d.), Flickr (Yahoo, n.d.), and Second life (SL) (Kemp \& Livingstone, 2006). Second Life, developed by Linden Lab, is a persistent three dimensional world, which allows "education designers in SL to create all manner of classrooms, lecture halls and campus landmarks" (Kemp \& Livingstone, 2006, p. 22).

The remainder of this section presents the background to VLS tools and features available for online teaching and learning, VLS usage behaviour in higher education, issues related to VLS usage and implications thereof.

\subsection{VLS tools and features}

A VLS is usually a browser-based application comprising of a range of tools. The tools, for example, include communication, student productivity and involvement, course management, assessment and content to support educational practices (WICHE Cooperative for Educational Technology, n.d.):

- Communication tool features include discussion forums, discussion management, electronic file exchange, internal mail, online journal/notes, real-time chat, whiteboard, announcements, wikis, audio and video conferencing, and virtual worlds.

- Student productivity tool features cover bookmarks, calendar/progress review, searching and filtering within a course, working offline/synchronizing, orientation/help, and personal development planning (PDP). 
- Student involvement tool features covers group work, community networking, and student profiles/portfolios.

- Course administration and management features incorporate authentication, course authorisation, registration integration with enrolment records, and course management.

- Assessment/progress tracking and reporting features covers test types, automated testing management, online marking tools, online grade book, student tracking, assignment-specific digital drop boxes, and surveys.

- Content authoring, delivery and management features include content authoring, content sharing/reuse, course templates, content-delivery and content and file management.

\subsection{VLS usage behaviour in higher education}

According to Welle-Strand and Thune (2003), universities are viewed as the main driving force to prepare graduates for advancement and competitiveness through the effective use of information and communication technology. The VLSs used in higher education have evolved to include advanced teaching tools and administrative and management functionality (Gallagher, 2003), as described in Section 2.1.

Several studies in the past addressed the issue of VLS usage from various perspectives. Examples of such studies include:

- The survey of instructors conducted by Branon and Essex (2001) on the use of synchronous and asynchronous tools in distance education reported that asynchronous communication was more helpful for in-depth, more thoughtful discussion, allowing all students to respond to a topic. Community building was one of the reasons given for using a synchronous chat tool.

- A survey of VLS usage conducted by Morgan (2003) at the University of Wisconsin revealed that content tools received heavier use than the other tools. Use was skewed in the form of content provision in the form of syllabi, course documents, staff information and announcements. Morgan (2003), noted that, while there was evidence that the VLS increased staff-student interaction, it was used mainly to administer quizzes and perform other administrative tasks rather than being used as a pedagogical tool.

- Beck (2005) alluded to a trend in higher education where VLSs were used for a "delivery" teaching style, as it facilitated easy distribution of lecture material and convenient submission of students' assignments.

- According to Kemp and Livingstone (2006), while virtual learning systems included various communication tools to enable staff-student interaction, they were mainly used as repositories for course related material. Educational content was typically stored in static documents, consisting of copies of presentation slides and word processor documents. Assessment and 
interactive features of VLSs were used less often, and the use of multi-media was less common as VLSs did not support the development of multi-media content.

- Vovides, Sanchez-Alonso, Mitropoulou and Nickmans (2007) made the observation that while VLSs have integrated capabilities to support learners and the learning process, it would appear that many lecturers used VLSs as a delivery method for the subject matter. There was an underutilisation of functionalities to present the learning material using multimedia.

- The findings of the study conducted by Oliver and Moore (2008) were as follows: content presentation tools were used to post static content and syllabi; more complicated tools such as the grade book and interactive tools such as discussion boards were being adopted more slowly; and communication tools were used typically one way from instructor to student.

- The findings of a survey of 862 faculty members at 38 institutions that used Blackboard, presented by Yueh and Hsu (2008), indicated that only a few faculty members used VLS functions to assess students or to nurture a more positive sense of community within their face-to-face classes. Most faculty members used instructional functions, such as publishing syllabi, sending email, and providing readings. The communicative and interactive features of online chat rooms and discussion forums and tools to facilitate group work were mostly unused.

- The results of an online survey conducted in 2007 at UKZN on the main uses of the Online Learning System (OLS) (Jackson, n.d.) by educators were as follows: 22 (65\%) respondents used some interaction and communication tools 'mainly for content distribution' or 'for content distribution only', 12 (35\%) respondents used a full range of learning and communication tools encompassing participation, peer review and reflection; and none of the respondents $(0 \%)$ used online marking and grading tools. These findings were consistent with a pattern of uneven VLS usage reported in other universities. An implication of these survey findings for this research was to ascertain whether the pattern of uneven VLS feature usage had changed after the official adoption of Moodle by UKZN for usage by educators and students.

- A study conducted by Rohleder, Bozalek, Carolissen, Leibowitz and Swartz (2008) on students' assessment of e-learning use in the context of a collaborative project between two South African Universities, reported both positive and negative evaluations.

- C. Brown and Czerniewicz (2008) conducted a study of information and communication technology (ICT) use in six higher education institutions across four South African provinces. The findings of their study confirm mainstream use of ICTs for information and communication and different frequency of use for specialised e-learning activities.

- A study conducted by (Czerniewicz \& C. Brown, 2009) on the relationship between policy, organisational culture and e-learning use from staff and student perspectives, reported a clear relationship between policy and the use of ICTs for teaching and learning. Organisational culture was cited as a key aspect for entrenchment of e-learning in an institution. 
- A study conducted by C. Brown and Czerniewicz (2010), on South African higher education students access to and the use of ICTs found that familiarity and experience with ICTs is a determining factor in students' digital lives.

- A survey conducted by Monaghan et al. (2011) aimed at developing a database of educational technologies used in schools and colleges of pharmacy reported the most frequently used educational technology was course management systems and the least frequently used technology was microblogging.

- A study was conducted by Lang and Pirani (2014) of US institutions with a Carnegie classification in order to understand the current and future state of VLS use in higher education. The ECAR report of undergraduate students and information technology (Dahlstrom, Walker \& Dziuban, 2013) reports that VLSs/LMSs were underutilised, and that academics use the VLSs for basic activities such as distributing course content to students. Students expressed the need for more engagement by improved communication with their lecturers, posting of interactive material and problem sets, as well as timely information on assessment grades.

\subsection{Challenges related to VLS usage}

According to Oliver (2001), a major concern regarding VLS use by academic staff is that content distribution tools for the dissemination of course syllabi and lecture notes/slides are emphasised over student interaction and engagement tools, namely discussions, sharing of information, development of artefacts, creating knowledge and analysing cases. He recommends that alternative tools should be sought to support analysis, synthesis and evaluation type learning activities.

The need for alternative tools is supported by G. Brown and Peterson (2008), who believe that students are developing incipient visual literacy using Flickr, communication skills using Facebook, team and organisational skills using the project management tool in Basecamp, and they are developing new kinds of learning in virtual worlds and in games. Many progressive educators are now conducting authentic learning using wikis, blogs, open source ePortfolios and personal learning environments. Phahlane and Kekwaletswe (2012) propose that VLSs (referred to LMSs in their article) should be interfaced with text messaging services through mobile phones.

According to Hurlburt (2008), blogs contained within VLSs offer very little in the way of personalisation of the virtual learning space when compared to blog environments such as WordPress or Blogger. Hurlburt (2008) argues that this limitation is attributed to VLS designs that are based on nineteenth and twentieth-century pedagogical models that fail to recognize the potential in social constructivist models for learning. According to Britain and Liber (2004), one major reason why VLSs are predominantly used for basic course management tasks and, consequently, why there has been little pedagogical innovation using these tools to date is that the first generation VLSs do not obviously support more radical or diverse learning activities. If the design of the software environment encourages a pattern of use that mimics traditional lecturer-student roles, there is little incentive for lecturers to adopt new approaches. 


\subsection{Implications for VLS usage in higher education}

The findings of previous studies by Morgan (2003), Oliver (2001), Vovides et al. (2007), Oliver and Moore (2008), and Yueh and Hsu (2008) illustrate that VLSs are used mostly for content distribution and communication from lecturer to students, while interaction and learning as well as assessment tools are used less often, if not at all. These findings support the statement made by Van der Valk (2008) that virtual learning systems hold real promise, but are unrealised in many cases. The theoretical background presented in Section 2.2 provides an overview of a selection of studies conducted in the international and local context of VLS use with varying foci, and provides the wider context for the study undertaken. It is evident from all the studies presented in that the full potential of VLS tools to support interactive learning is not being realised by the majority of lecturers/educators, and that alternative tools are sought to support diverse learning activities.

This paper reports on a study to investigate the usage of VLSs at two South African higher education institutions to support teaching and learning activities. The study focused on two aspects: VLS feature usage and the challenges related to VLS usage in general. The study was undertaken to gain insights into the current status of the usage of two different VLSs by educators in two higher education institutions in South Africa. In addition, this study attempts to understand the challenges that impact on the usage of the features of e-learning tools and technology, via the medium of VLSs in institutions of higher education, to support teaching and learning activities/tasks, and management of courses. VLSs are by no means dead and continue to be at the forefront of attention for educators and administrators planning to integrate technology into education. Administrators need to factor these systems for institutional planning, educators need to adopt transformative pedagogical practices to make effective and optimal use of VLS features, researchers need to conduct data mining to learn more about student course activity, and finally designers need to evolve the design of VLS based on the usage and experiences of educators into adaptive, personalised learning platforms.

\section{RESEARCH METHODOLOGY}

This section focuses on the research questions that guided the study, the research approach and design adopted, the sampling techniques, data collection and data analysis methods used.

A case study research strategy was deployed to investigate VLS usage patterns and issues from an educator's perspective using two cases, namely the University of KwaZulu-Natal (UKZN) and the Durban University of Technology (DUT). Moodle is the most extensively used VLS at UKZN and Blackboard at DUT. The primary focus of the case studies was therefore on the use of Moodle and Blackboard.

The study focused on three key research questions to guide the research to investigate the gap between the VLS features available and those actually used for online teaching and learning:

1. What is the extent and frequency of VLS features usage by educators at DUT and UKZN?

2. What are the clusters of VLS features used by educators at DUT and UKZN?

3. What are the challenges associated with VLS usage by educators at DUT and UKZN? 
A combination of quantitative and qualitative instruments were used to collect data (Venkatesh, Brown \& Bala, 2013).

A literature review was undertaken to understand the generic tools and features of VLSs, their usage patterns in higher education, and VLS usage challenges.

Primary data collection techniques included in-depth semi-structured interviews and structured surveys in two higher education institutions in the province of KwaZulu-Natal. The interview schedule and questionnaire incorporated questions on educators' usage of VLS tools and features identified in Section 2.1, and issues surrounding their usage. The research instruments were piloted with four educators from UKZN prior to actual data collection to check for potential problems and refined accordingly.

A purposive sampling technique (Sekaran \& Bougie, 2010) was used in the qualitative part of the study, to select educators that were currently using a VLS, with a minimum of one year's experience with a VLS. Twenty six interviews were conducted, with ten interviews at DUT and sixteen interviews at UKZN. The interviews were recorded and transcribed.

The target population for the survey comprised educators in higher education that were using the university-supported VLSs for teaching and learning purposes. Members of the target population were identified with the assistance of responsible units for managing educational technology usage, namely, the 'E-learning' unit within the 'Centre for Excellence in Learning and Teaching' at DUT and the 'Academic Computing' Unit of the 'Information and Communication Services Department' at UKZN. A census sampling technique was adopted for the survey based on official records of all teachers using the two formally adopted VLSs. A total of 579 teachers, 358 from UKZN and 221 from DUT were then invited via email to participate in the study. A total of 108 responses were received from educators with 36 responses from DUT and 72 responses from UKZN.

Ethical clearance was obtained from the relevant authorities before commencing with the collection of data. The identities of interviewees and survey respondents were not disclosed during the publication of the results of this research. In addition, an informed consent form was used for participants to sign before they engaged in the research.

Thematic analysis was used to analyse qualitative data. According to Guest, MacQueen and Namey (2011, p. 15), the approach to qualitative data involves the "reduction of texts to codes that represent themes or concepts and the application of quantitative methods to find patterns in the relations among the codes". The transcribed interviews were imported into a computer software analysis tool NVivo (QSR International, n.d.). Analysis was performed using codes to represent subcategories of VLS tools and features usage.

Descriptive and inferential statistics were used to analyse the quantitative data. Descriptive statistics used were measures of central tendency, variation, and frequency tables (Sekaran \& Bougie, 2010, p. 440). Inferential statistics used to analyse quantitative data in this study were analysis of variance (ANOVA), Cronbach's alpha statistic, and t-tests. ANOVA is defined as an "analysis of variance which tests for significant mean differences in variables among multiple groups" Rohleder et al. (2008, p. 435). Cronbach's alpha statistic may be defined as "a reliability coefficient that indicates how well the items in a set are positively related to one another" (Sekaran \& Bougie, 2010, p. 324). A test using the t-statistic establishes whether two means collected from independent 
samples differ significantly (Sekaran \& Bougie, 2010, p. 446).

\section{FINDINGS AND ANALYSIS}

This section presents the qualitative (Section 4.1) and quantitative (Section 4.2) findings and analysis for the research undertaken.

\subsection{Qualitative findings and analysis}

This section represents the category/theme of actual usage and sub-themes representing the tools and features of a virtual learning system (VLS) used for online/blended teaching and learning. All references in the interview transcripts that referred to the current usage of the VLS were coded as "actual system usage". Subthemes were identified by way of reference to the VLS tools and features used. The theme and subthemes provides insight into VLS feature usage scope/extent, clusters of VLS features used, and the issues associated with VLS usage.

\subsubsection{DUT Blackboard actual system usage}

Ten educators, five female and five male, were interviewed from various disciplines at DUT, including fine arts, management, health sciences, and engineering. Educators interviewed were teaching at both the undergraduate and postgraduate levels of study. All of the interviewees had been using Blackboard in their teaching practice for over a year. All of the interviewees had completed the 'Pioneers Online' training programme, which was a short certificate course, presented by the Education Technology Unit at DUT within the Centre for Excellence in Learning and Teaching (CELT). Some of the educators had also completed the intermediate and advanced training courses in Blackboard.

Table 1 provides a summary of the Blackboard's tools and associated features used by educators interviewed at DUT, extracted from the interview transcript excerpts stored under the coded theme "actual system usage", further differentiated by sub-themes representing tool usage.

Additional, or alternative, tools used by educators at DUT for teaching include: Skype for real time chats with students; Facebook, for educational communication and mentoring; Flickr, an online photo management and sharing application for visual content; spreadsheets for recording and analysing assessment marks; authoring tools like Dreamweaver to create dynamic web pages for courses, a plagiarism tool, and public blogs where students uploaded design portfolios and lecturers posted comments on the design.

These findings support the observation by Blinco et al. (2004) that the choice of options that facilitate learning is increasing as a result of the availability of a wide range of information and communications technologies, and that choice of tools depends on the instructional strategy. 
Table 1: DUT Blackboard actual system usage

\begin{tabular}{|l|l|}
\hline Blackboard tools & Features usage \\
\hline Communication & $\begin{array}{l}\text { Blog discussion; threaded discussion forums; announce- } \\
\text { ments; email; course calendar; file exchanges }\end{array}$ \\
\hline Administration & $\begin{array}{l}\text { Grouping of students; selective release via hiding of docu- } \\
\text { ments; selecting course tools; organising content; copying } \\
\text { course resources; storing students' submissions as artefacts; } \\
\text { storing multi-media content in media library; managing as- } \\
\text { sessments and submissions. }\end{array}$ \\
\hline Content & $\begin{array}{l}\text { Content upload; creation of learning objects using learning } \\
\text { module tool; quizzes; glossary; using Web links. }\end{array}$ \\
\hline Assessment & $\begin{array}{l}\text { Online quizzes; online self-tests; online assignments; online } \\
\text { marking and grading; online assessment feedback; import- } \\
\text { ing grade book; grading forms used for assignments; peer } \\
\text { evaluation; grading student posts; exporting grade book to } \\
\text { spreadsheet; statistics for test questions; conducting surveys. }\end{array}$ \\
\hline Student productivity and involvement & $\begin{array}{l}\text { Journal entries; group work; student profile; self-tests; stu- } \\
\text { dent journal. }\end{array}$ \\
\hline Tracking & $\begin{array}{l}\text { Student marks in gradebook; online assignment submission; } \\
\text { student online activities. }\end{array}$ \\
\hline
\end{tabular}

\subsubsection{UKZN Moodle actual system usage}

Sixteen educators, nine female and seven male, were interviewed from several disciplines at UKZN, including telehealth, information technology education, nursing, information systems and technology, pharmacology, education, Internet studies, computer science, genetics, engineering, mathematics, law, and dietetics and human nutrition. The level of study taught included both undergraduate and postgraduate courses. The minimum length of usage of Moodle by interviewees in the courses taught was a year. Some of the interviewees had attended introductory workshops on Moodle run by the Academic Computing Department while others had learnt to use the VLS through selfexperimentation.

Table 2 provides a summary of the Moodle tools and associated features currently used by educators interviewed at UKZN, extracted from the interview transcript excerpts stored at the coded theme "actual system usage", which were further differentiated by sub-themes representing tool usage.

Additional or alternative tools used by educators at UKZN include: authorPoint (AuthorGEN, n.d.), for multimedia e-learning presentations; Dimdim (n.d.), an open source video conferencing tool for distance learning programmes; Elluminate (Blackboard, n.d.), a web conferencing program, to support uploading of presentations on the whiteboard; social networking software like Facebook and Edmodo, a learning platform for teacher-student communication and resource sharing; Mendeley (n.d.), a referencing and bibliographic tool for postgraduate research based programmes; Turnitin (n.d.), a plagiarism text-matching tool; Zotero (n.d.), used by students and researchers to collect, 
Table 2: UKZN Moodle actual system usage

\begin{tabular}{|l|l|}
\hline Moodle tools & Features usage \\
\hline Communication & $\begin{array}{l}\text { Blogs; threaded discussion forums; wikis; chats; announce- } \\
\text { ments/ notices; email; course calendar; file uploading and } \\
\text { sharing. }\end{array}$ \\
\hline Administration & $\begin{array}{l}\text { Grouping of students; selective release of documents; hid- } \\
\text { ing courses/documents; setting up and organising courses; } \\
\text { student evaluation surveys. }\end{array}$ \\
\hline Content & $\begin{array}{l}\text { Content upload; creating a resource library of materials; } \\
\text { creating course glossary, lessons; linking to websites/Internet } \\
\text { resources; creating or uploading multi-media content. }\end{array}$ \\
\hline Assessment & $\begin{array}{l}\text { Online quizzes; online tests; assignments; online marking; } \\
\text { grade book; peer review workshops; grading student online } \\
\text { participation; exporting grade book. }\end{array}$ \\
\hline Student productivity and involvement & Student reflective journal; group work; student profile. \\
\hline Tracking & $\begin{array}{l}\text { Student marks; assignment submission; student usage stat- } \\
\text { istics and activity reports. }\end{array}$ \\
\hline
\end{tabular}

organize, cite, and share research sources; and Second Life, a three dimensional environment used by students to create an educational space in Virtual World.

\subsubsection{Analysis of actual VLS usage at DUT and UKZN}

This section presents an analysis of the interview findings, highlighting the similarities and differences in system usage at DUT and UKZN, together with motivations for tool usage and issues associated with usage.

Commonly used communication tools across both institutions were online discussion forums, email, calendars, announcements/noticeboard/news, forums and file exchanges. The discussion forums at both institutions were used for a variety of purposes, namely, for general inquiries, for providing an opportunity for all students to contribute to topic discussions, and in some instances grading of student participation in online discussions. Interviewees at DUT did not report using the chat facility as all their courses offered were face-to-face. The synchronous chat tool was used only in special instances at UKZN to support courses offered on a pure distance basis. These findings may well be pedagogically sound given that a survey of instructors conducted by Branon and Essex (2001) on the use of synchronous and asynchronous tools in distance education, reported asynchronous communication to be suitable for in-depth discussion, allowing all students to respond to a topic, and synchronous communication being used to support community building.

The Web 2.0 tools were used less often, with blogs being used more than wikis. Blogs were used less often at UKZN, while preferred over the asynchronous discussion forum at DUT. At DUT, public blogs were preferred over the blogging discussion tool within Blackboard to foster a public community of learning, especially in the fine arts discipline. There is no built-in wiki tool within 
Blackboard, which explains the lack of usage at DUT. Users can link to an external wiki but they need a password, which was reported to be a deterrent to usage. Wikis were used selectively by educators at UKZN. The outcome of the study was somewhat similar to those reported by Hurlburt (2008) in that participants of both studies preferred using external blogs. However, the reason for the preference in this research was because internal blogs did not match public environments such as WordPress or Blogger.

There was a similarity in the usage patterns of communication, course administration, course content, course assessment, student involvement and productivity, and student tracking tools for both DUT and UKZN. Common uses of a VLS were content delivery, communication, administration, online quizzes, and online assignment submissions. There was less emphasis placed on the use of a VLS for student tracking and student productivity and involvement. These findings confirm those of the study by Oliver and Moore (2008), where content presentation tools were more favoured over assessment and interactive tools, and communication tools were used mainly in broadcast mode. In addition, these results confirmed the finding of Beck (2005) that virtual learning systems were used for a "delivery" teaching style, as it facilitated easy distribution of lecture material and convenient submission of students' assignments.

The findings on the use of additional or alternative tools used by educators at DUT and UKZN corresponds to the findings of Ng'ambi and Bozalek (2013) who reported an increase in the usage of emerging technologies both in South Africa and abroad. These emerging technologies refer to the use of social media, social networking, instant messaging, Zotero, Mendeley and wikis.

Some of the issues and motivations relating to VLS tool usage reported by educators were as follows:

- Some interviewees at UKZN reported that their students were reluctant to engage in online forum discussions. Online communication was therefore typically one-way from lecturer to students. This result confirms the finding reported by G. Brown and Peterson (2008) that the mode of VLS communication was primarily broadcast in nature, from the faculty member to the student.

- Self-tests in the form of quizzes appear to be favoured over formal online tests, due to the logistics involved in setting up the tests and the physical facilities needed.

- The use of journals/diaries was reported to be suitable for some disciplines while not for others.

- Peer reviewing tools were used mostly for postgraduate programmes.

- The grade book was not widely used, as educators at both institutions were comfortable using a spreadsheet for the capture and statistical analysis of marks. Those that did use the grade book still exported marks to a spreadsheet for performing statistical analysis.

- Online submission of assignments was a commonly used facility across both institutions. While the feature was used, educators reported that some students preferred handing in hard copy assignments or attaching assignments to emails. 
- Moodle has a workshop facility where peer reviews of assignments can be performed, which was rarely used as most educators did not know about the existence of this tool and its purpose (apart from not knowing how to use the tool).

- Blackboard has a learning module while Moodle has a facility to create lessons, which were scarcely used.

- Online marking was performed by downloading assignments, marking them using the comments facility in MS Word or Adobe Acrobat, uploading marked assignments onto the system, and capturing the individual marks in the grade book or spreadsheet.

- Some of the educators interviewed at both DUT and UKZN, reported that they had not used synchronous tools such as chats and videoconferencing tools nor had they conducted online tests. This result pertaining to online testing confirms the findings made by Oliver and Moore (2008) that some instructors were not using instructional functions, such as conducting quizzes or collecting and returning assignments, and that the online grade book and interactive tools such as discussion boards were being adopted more slowly. However, another explanation for this finding is that those educators that supplement their courses with a VLS employ tools differently from those who teach fully online.

- Staff at UKZN welcomed the integration of Turnitin, a plagiarism checking tool, into Moodle. Only a few educators indicated that they used the Turnitin online marking facility.

- Some educators at both institutions acknowledged that VLSs, such as Blackboard or Moodle, have many good tools and features, but do not have everything that lecturers or students need. One view expressed was that VLSs would be replaced by learning portals, where the student decides the tools needed to facilitate and manage his/her own learning. These views support those expressed by Blinco et al. (2004) regarding the availability of a wide range of information and communications technologies to educators to meet diverse needs. In addition, the need for more specialised educational tools confirms the view of Oliver (2001) who suggests that instructional strategies should form the basis for selecting educational tools.

\subsection{Quantitative findings and analysis}

This section presents the quantitative findings and data analysis on actual system usage.

\subsubsection{DUT demographic results}

The majority of DUT respondents were lecturers and senior lecturers, with academic ranks "other" and associate professors representing a small percentage, as depicted in Table 3.

The highest frequency of academic levels taught were as follows: undergraduate courses, followed by mostly undergraduate with some postgraduate courses; then postgraduate courses only; and lastly, mostly postgraduate and some undergraduate courses, as displayed in Table 4. 
Table 3: Academic rank

\begin{tabular}{|l|r|r|r|r|}
\hline & Frequency & Percent & Valid percent & Cumulative percent \\
\hline Lecturer & 16 & 44.4 & 44.4 & 44.4 \\
Senior lecturer & 12 & 33.3 & 33.3 & 77.8 \\
Associate professor & 2 & 5.6 & 5.6 & 83.8 \\
Other & 6 & 16.7 & 16.7 & 100.0 \\
\hline Total & 36 & 100.0 & & \\
\hline
\end{tabular}

Table 4: Level of study taught

\begin{tabular}{|l|r|r|r|r|}
\hline & Frequency & Percent & Valid percent & Cumulative percent \\
\hline Undergraduate courses only & 17 & 47.2 & 47.2 & 47.2 \\
Postgraduate courses only & 5 & 13.9 & 13.9 & 61.1 \\
Mostly undergraduate with some & 11 & 30.6 & 30.6 & 91.7 \\
postgraduate & & & & 100.0 \\
$\begin{array}{l}\text { Mostly postgraduate with some } \\
\text { undergraduate }\end{array}$ & 3 & 8.3 & 8.3 & \\
\hline Total & 36 & 100.0 & & \\
\hline
\end{tabular}

Blackboard was reported to be the VLS being the most used currently at the two institutions, followed by Moodle, and WebCT (prior to its acquisition by Blackboard), as shown in Table 5 .

The highest frequency of length of usage reported was "from 1 to less than 3 years"; followed by a tie between "less than 1 year" and " 5 years or more"; and the lowest frequency of length of usage is "from 3 to less than 5 years", as illustrated in Table 6.

The highest frequency for number of distinct online/hybrid courses taught was "between 1 and 3", followed by "greater than 6" and "between 4 and 6", as depicted in Table 7.

\subsubsection{Feature usage extent and feature usage frequency for DUT case study}

The extent and frequency of VLS usage at DUT is illustrated in Figure 1. The graph indicates the usage percentages for each of the actual system items (from "not at all" through to "usually") pertaining to the following question: "Which of the following VLS functions/features have you utilised for your courses and to what extent?"

Table 5: VLS current/most currently used

\begin{tabular}{|l|r|r|r|r|}
\hline & Frequency & Percent & Valid percent & Cumulative percent \\
\hline WebCT & 4 & 11.1 & 11.1 & 11.1 \\
Moodle & 8 & 22.2 & 22.2 & 33.3 \\
Blackboard & 22 & 61.1 & 61.1 & 94.4 \\
Other & 2 & 5.6 & 5.6 & 100.0 \\
\hline Total & 36 & 100.0 & & \\
\hline
\end{tabular}


Table 6: Length of VLS usage

\begin{tabular}{|l|r|r|r|r|}
\hline & Frequency & Percent & Valid percent & Cumulative percent \\
\hline less than 1 year & 7 & 19.4 & 19.4 & 19.4 \\
from 1 to less than 3 years & 17 & 47.2 & 47.2 & 66.7 \\
from 3 to less than 5 years & 5 & 13.9 & 13.9 & 80.6 \\
5 years or more & 7 & 19.4 & 19.4 & 100.0 \\
\hline Total & 36 & 100.0 & & \\
\hline
\end{tabular}

Table 7: Number of distinct online/hybrid courses taught

\begin{tabular}{|l|r|r|r|r|}
\hline & Frequency & Percent & Valid percent & Cumulative percent \\
\hline between 1 and 3 & 24 & 66.7 & 68.6 & 68.6 \\
between 4 and 6 & 5 & 13.9 & 14.3 & 82.9 \\
greater than 6 & 6 & 16.7 & 17.1 & 100.0 \\
\hline Total & 35 & 97.2 & 100.0 & \\
\hline Missing & 1 & 2.8 & & \\
\hline
\end{tabular}

The functions at the top of the graph are those least used. Analysis of the "total score" (average frequency score) of the following features, namely, posting course content; presenting course information; course announcements/ notices/news; course calendar and schedule; e-mail communication; creating lessons; online quizzes/self-tests; online assignment submission; online threaded discussion forums; and online glossary shows a higher usage as these scores were above a neutral score of 3. Features that scored lower than the neutral score of 3 were as follows: online marking of assessments/activities with grading and comments; online tests; peer evaluation of assignments; tracking student participation in online discussion forums; grading student participation in online discussion forums; peer reviews of student posts; grading of peer reviews; publishing marks in grade book; online real-time chat with students; wikis; blogs; shared whiteboard; file exchanges; student online journals; online surveys and online polls. A modest percentage, namely, $38.5 \%$ of the VLS features display high usage, while $61.5 \%$ of the VLS features displays lower than average usage for the institution DUT.

\subsubsection{UKZN demographic results}

The majority of the respondents at UKZN were lecturers followed by academic ranks termed "other", senior lecturers, associate professors, and professors, as depicted in Table 8.

Table 9 shows that the highest frequency of the academic levels taught were mostly undergraduate, with some postgraduate courses, followed by undergraduate courses only, mostly postgraduate with some undergraduate courses, and lastly, postgraduate courses only.

Table 10 depicts Moodle to being the most used VLS at UKZN, followed by "other", with Blackboard and the Open Learning System in third place.

Table 11 shows that the highest frequency of length of usage is "from 1 to less than 3 years"; 
Shared whiteboard

Grading student participation in online discussion... Peer evaluation of assignments Grading of peer reviews Wikis Online polls

Online real-time chat with students Peer reviews of student posts Blogs Online surveys

Tracking student participation in online discussion.. Online test Student online journals File exchanges Online threaded discussion forum Online glossary Online quizzes/self tests Publishing marks in grade book Online marking of assessments/ activities with.. Creating lessons Course announcement/ notices/ news Course calendar and schedule Online assignment submission E-mail communication Presenting course information Posting course content $\begin{array}{lllllllllll}0 \% & 10 \% & 20 \% & 30 \% & 40 \% & 50 \% & 60 \% & 70 \% & 80 \% & 90 \% & 100 \%\end{array}$

Not at all $\quad$ Rarely $\square$ Sometimes $\square$ Often $\square$ Usually $\square$ Missing

Figure 1: Frequency of feature usage of VLS at DUT

Table 8: Academic rank

\begin{tabular}{|l|r|r|r|r|}
\hline & Frequency & Percent & Valid percent & Cumulative percent \\
\hline Lecturer & 33 & 45.8 & 45.8 & 45.8 \\
Senior lecturer & 13 & 18.1 & 18.1 & 63.9 \\
Associate professor & 8 & 11.1 & 11.1 & 75.0 \\
Professor & 4 & 5.6 & 5.6 & 80.6 \\
Other & 14 & 19.4 & 19.4 & 100.0 \\
\hline Total & 72 & 100.0 & 100.0 & \\
\hline
\end{tabular}


Table 9: Level of study taught

\begin{tabular}{|l|r|r|r|r|}
\hline & Frequency & Percent & Valid percent & Cumulative percent \\
\hline Undergraduate courses only & 21 & 29.2 & 30.0 & 30.0 \\
Postgraduate courses only & 4 & 5.6 & 5.7 & 35.7 \\
Mostly undergraduate with some & 33 & 45.8 & 47.1 & 82.9 \\
postgraduate & & & & 100.0 \\
$\begin{array}{l}\text { Mostly postgraduate with some } \\
\text { undergraduate }\end{array}$ & 12 & 16.7 & 17.1 & \\
\hline Total & 70 & 97.2 & & \\
\hline Missing system & 2 & 2.8 & & \\
\hline Total & 72 & 100.0 & & \\
\hline
\end{tabular}

Table 10: VLS current/most currently used

\begin{tabular}{|l|r|r|r|r|}
\hline & Frequency & Percent & Valid percent & Cumulative percent \\
\hline WebCT & 2 & 2.8 & 2.8 & 2.8 \\
Moodle & 65 & 90.3 & 90.3 & 93.1 \\
Blackboard & 2 & 2.8 & 2.8 & 95.8 \\
Other & 3 & 4.2 & 4.2 & 100.0 \\
\hline Total & 72 & 100.0 & & \\
\hline
\end{tabular}

followed by "from 3 to less than 5 years", and " 5 years or more" and the lowest frequency of length of usage is "less than 1 year".

The highest frequency for number of distinct online/hybrid courses taught is "between 1 and 3", followed by "greater than 6" and "between 4 and 6", as illustrated in Table 12.

\subsubsection{Feature usage extent and feature usage frequency for UKZN case study}

The extent and frequency of VLS usage at UKZN is illustrated in Figure 2. The graph indicates the usage percentages for each of the actual system items (from "not at all" through to "usually") pertaining to the following question: "Which of the following VLS functions/features have you utilised for your courses and to what extent?"

Analysis of the "total score" (average frequency score) of the following features, namely, posting

Table 11: Length of VLS usage

\begin{tabular}{|l|r|r|r|r|}
\hline & Frequency & Percent & Valid percent & Cumulative percent \\
\hline less than 1 year & 7 & 9.7 & 9.7 & 9.7 \\
from 1 to less than 3 years & 44 & 61.1 & 61.1 & 70.8 \\
from 3 to less than 5 years & 12 & 16.7 & 16.7 & 87.5 \\
5 years or more & 9 & 12.5 & 12.5 & 100.0 \\
\hline Total & 72 & 100.0 & & \\
\hline
\end{tabular}


Table 12: Number of distinct online/hybrid courses taught

\begin{tabular}{|l|r|r|r|r|}
\hline & Frequency & Percent & Valid percent & Cumulative percent \\
\hline between 1 and 3 & 44 & 61.1 & 62.0 & 62.0 \\
between 4 and 6 & 10 & 13.9 & 14.1 & 76.1 \\
greater than 6 & 17 & 23.6 & 23.9 & 100.0 \\
\hline Total & 71 & 98.6 & 100.0 & \\
\hline Missing system & 1 & 1.4 & & \\
\hline Total & 72 & 100.0 & & \\
\hline
\end{tabular}

Table 13: Usage clusters for DUT and UKZN

\begin{tabular}{|l|r|r|r|}
\hline Scale & Cronbach's alpha (all) & DUT & UKZN \\
\hline Communication cluster & 0.762 & 0.86 & 0.693 \\
Management cluster & 0.772 & 0.794 & 0.763 \\
Content cluster & 0.822 & 0.882 & 0.758 \\
Pedagogic cluster & 0.874 & 0.9 & 0.849 \\
\hline
\end{tabular}

course content; presenting course information; course announcements/notices/news; course calendar and schedule; and email communication shows a higher usage as these scores were above a neutral score of 3. Features that scored lower than the neutral score of 3, implying lower than average usage, were as follows: online assignment submission; online marking of assessments/activities with grading and comments; online quizzes/self-tests; online tests; peer evaluation of assignments; tracking student participation in online discussion forums; grading student participation in online discussion forums; peer reviews of student posts; grading of peer reviews; publishing marks in grade book; online threaded discussion forums; online real time chat with students; wikis; blogs; shared whiteboard; file exchanges; student online journals; creating lessons; online glossary; online surveys and online polls. A small percentage, namely, 19.2\% of the VLS functions display high usage, while 80.8 of VLS functions display lower than average usage for the institution UKZN.

\subsubsection{Usage clusters}

The Cronbach alpha statistic was applied for the whole sample comprising DUT and UKZN survey responses to all the actual system usage items pertaining to the following question: "Which of the following VLS functions/features have you utilised for your courses and to what extent?"

The resulting Cronbach alpha value of .912 was obtained, which was excellent for analysis. Table 13 depicts the four usage clusters, namely communication, management, content and pedagogic, that were derived from actual system usage responses. The Cronbach's alpha values were, on the whole, more than 0.7, for the whole sample, and for the institutions DUT and UKZN, which were tabulated separately, based on survey responses received. 
Peer evaluation of assignments

Wikis

Shared whiteboard Grading of peer reviews

Blogs

Online polls

Student online journals

Peer reviews of student posts

Online test

Publishing marks in grade book

Online surveys

Grading student participation in online discussion..

Creating lessons

Online real-time chat with students

Online glossary

Tracking student participation in online discussion...

File exchanges

Online marking of assessments/ activities with...

Online quizzes/self tests

Online assignment submission

Online threaded discussion forum

E-mail communication

Course calendar and schedule

Course announcement/ notices/ news

Posting course content

Presenting course information
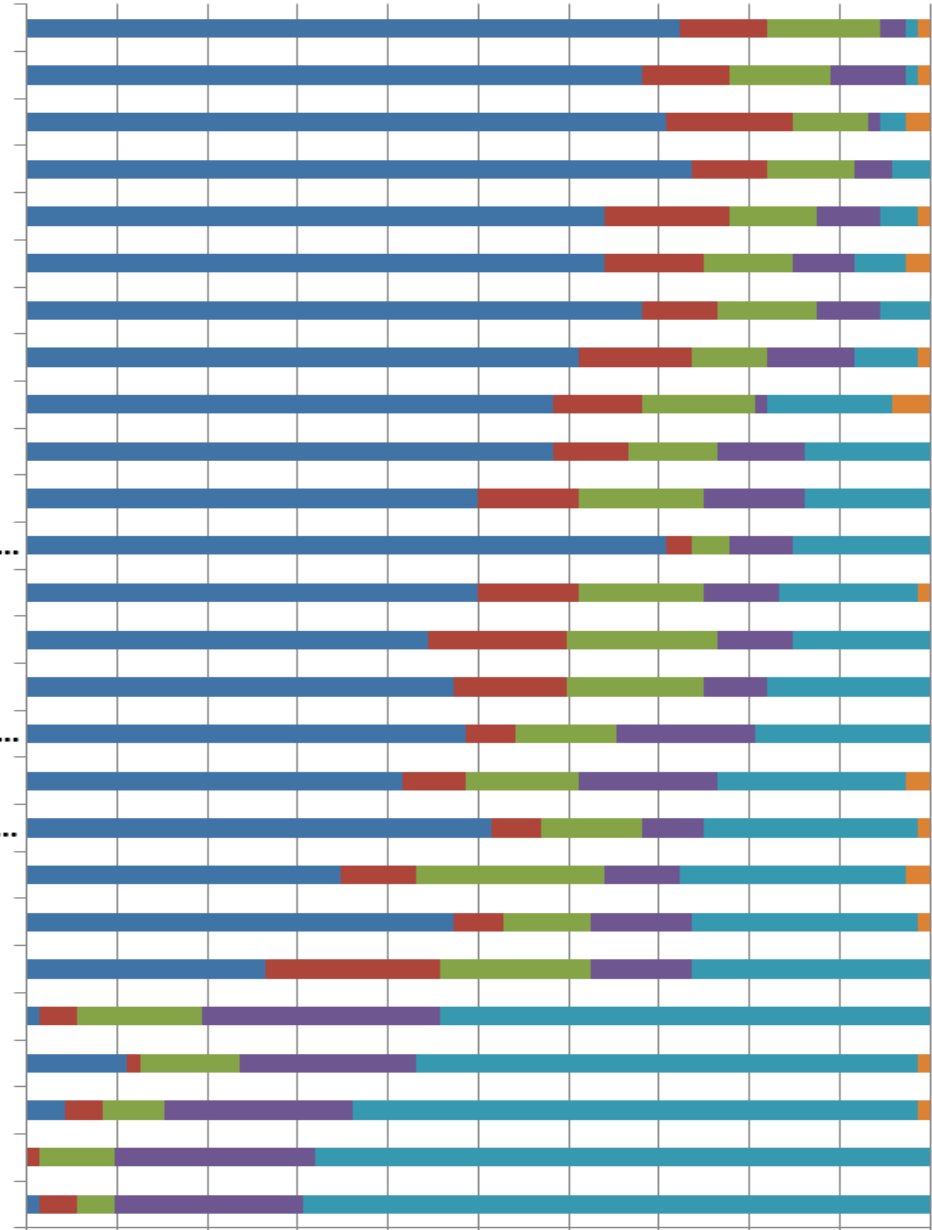

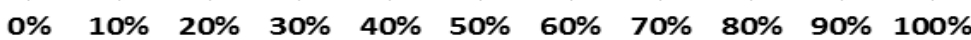

Not at all $\square$ Rarely Sometimes $\square$ Often Usually $\square$ Missing

Figure 2: Frequency of feature usage of VLS at UKZN 
Table 14: Descriptive statistics of usage clusters for DUT and UKZN

\begin{tabular}{|l|l|r|r|r|r|}
\hline & Institution & N & Mean & Std Deviation & Std Error Mean \\
\hline \multirow{2}{*}{ Communication cluster } & DUT & 36 & 2.9178 & .88286 & .14714 \\
& UKZN & 72 & 2.8450 & .68345 & .08054 \\
\hline \multirow{2}{*}{ Management cluster } & DUT & 36 & 2.2037 & 1.15546 & .19258 \\
& UKZN & 72 & 2.8450 & 1.22548 & .14442 \\
\hline \multirow{2}{*}{ Content cluster } & DUT & 36 & 4.2361 & .97458 & .16243 \\
& UKZN & 72 & 4.5486 & .71286 & .08401 \\
\hline \multirow{2}{*}{ Pedagogic cluster } & DUT & 36 & 2.5955 & .96503 & .16084 \\
& UKZN & 72 & 2.0888 & .87671 & .10332 \\
\hline
\end{tabular}

\subsubsection{Analysis of cluster usage at DUT and UKZN}

The column "Mean" in Table 14 presents the average usage score for the 4 usage clusters developed for actual system usage responses. A higher mean value implies more frequent usage. As can be seen from Table 14, the content cluster was used more than the other clusters. Analysis (independent samples t-test) shows that average usage at DUT (2.5955) of the pedagogic cluster is significantly greater than that at UKZN (2.0888), $p=0.007$.

\section{CONCEPTUAL MODEL OF VLS USAGE COMPONENTS}

The findings of the study were integrated into a conceptual model of VLS usage components with relationships to VLS features and VLS usage challenges, as illustrated in Figure 3. The dashed arrows refer to the fact that virtual learning system features and virtual learning system usage challenges represents the point of reference for actual system usage. Each of the components is described in the remainder of this section, highlighting their association with the outcomes of the research questions, as listed in Section 3.

\subsection{The extent and frequency of VLS feature usage by educators at DUT and UKZN}

According to Petter, DeLone and McLean, system use refers to the

degree and manner in which staff and customers utilize the capabilities of an information system, for example the amount of use, frequency of use, nature of use, appropriateness of use, extent of use, and purpose of use. (Petter, DeLone \& McLean, 2008, p. 239)

The quantitative findings of the survey conducted among educators at UKZN and DUT highlighted the scope of individual VLS features used for teaching and learning purposes, as well as the frequency of usage of these individual features. The feature usage extent included 26 features that were surveyed, as depicted in Figures 1 and 2. The feature usage frequency measure used ranged from 


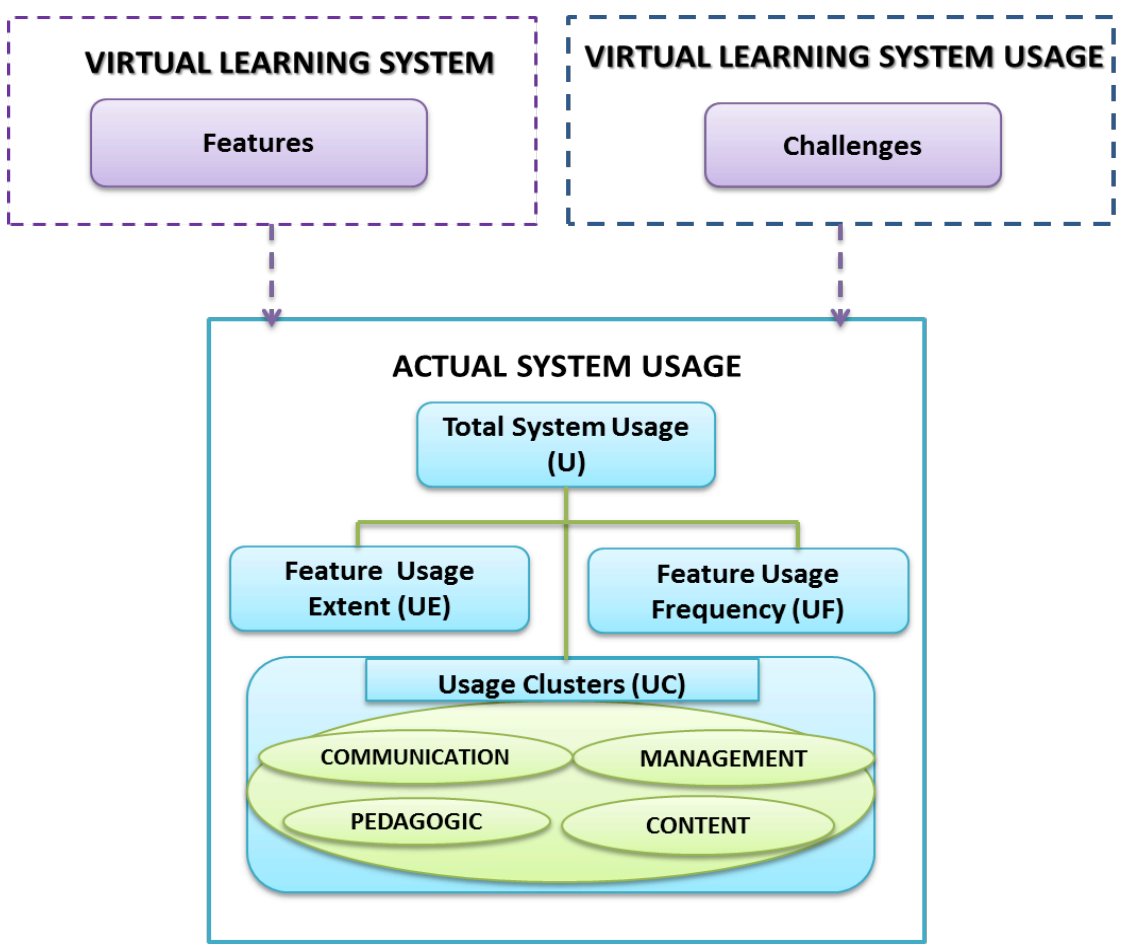

Figure 3: VLS usage components

"not at all", scored at 1, to "usually", scored at 5. High usage was associated with average frequency scores above the neutral score of 3 . Low usage was associated with average frequency scores below the neutral score of 3 . A modest proportion, namely, (10 out of 26 ) or $38.5 \%$ of the VLS features displayed high usage, while (16 out of 26 ) or $61.5 \%$ of the VLS features displayed low usage for the institution DUT, as described in Section 4.2.2. The findings suggest that content, communication, and pedagogic (learning and assessment) tool features enjoyed higher usage at the institution DUT as their average frequency scores were above 3.

A small proportion, namely, (5 out of 26 ) or $19.2 \%$ of the VLS functions displayed high usage, while (21 out of 26 ) or $80.8 \%$ of VLS features displayed lower than average usage for the institution UKZN as described in Section 4.2.4. The findings suggest that content and communication tool features enjoyed higher usage at UKZN as their average frequency scores were above 3. A possible explanation for this result was that all the DUT educators had completed a course through CELT, whereas few educators at UKZN had undertaken a formal course. This result suggests that staff development and support seems to be an important aspect of VLS usage, which deserves further research.

\subsection{The clusters of VLS features used by educators at DUT and UKZN}

The quantitative analysis of the survey conducted among educators at DUT and UKZN identified four clusters or groupings of VLS tool usage, namely communication, management, content and pedagogic 
(in this study defined as learning and assessment), which is depicted in Table 13. The content usage cluster was used more than the other clusters as depicted in Table 14. Analysis (independent samples t-test) shows that average usage at DUT (2.5955) of the pedagogic cluster namely, "learning and assessment", is significantly greater than that at UKZN (2.0888), $p=0.007$, as discussed in Section 4.2.6. There is no significant difference in the average usage of the communication and management cluster between the two institutions.

The findings of this study confirmed the findings of previous studies, discussed in Yueh and Hsu (2008), where the actual use of VLSs revealed that some functions were used more often than others. These findings point to the need for more qualitative research into why this is so and whether the uptake relates to pedagogical issues or other aspects.

\subsection{The challenges associated with VLS usage by educators at DUT and UKZN}

The challenges associated with VLS usage raised by educators included the following: student apathy in engaging in online discussion forums; logistical issues involved in setting up online tests; lack of suitability of tools (related to discipline, level and type of programme); awareness and training issues for more advanced teaching tools; reservations on the reliability and accuracy of using gradebook for maintaining records of students' marks; cumbersome online marking and publishing tools. These challenges can be classified as system, user, pedagogic and organisational related, which explains why certain VLS features display lower than expected usage.

These findings correspond to the challenges highlighted by Bagarukayo and Kalema (2015) with regards to e-learning usage in South African Universities, namely infrastructural constraints, demographic divides, staffing issues, organisational issues, learner issues, and pedagogical issues.

Mtebe (2015) proposes a number of strategies for overcoming challenges and maximising the usage of VLSs in institutions, which include improving system usability, enhancing support services, making use of mobile applications and complementing with social media.

\section{CONCLUSION}

New educational technology services and features are driven by advances in technology and a growing market. Despite the adoption of VLSs by higher education institutions, academic usage of system features is limited.

This paper provided insight into current levels and patterns of usage of the tools and features of VLSs and issues associated with their usage. The VLS feature usage results for DUT and UKZN were found to be similar in that both institutions showed a pattern of higher usage of content and communications features. However, DUT, in contrast to UKZN, also showed a higher usage of learning and assessment tool features. Analysis of VLS cluster feature usage indicated that the content usage cluster was used more than the communication, management, and pedagogic clusters at both DUT and UKZN. In addition, the average usage of the pedagogic cluster at DUT was significantly greater 
at DUT than UKZN. The challenges related to VLS usage at both DUT and UZN were wide ranging embracing system, user, pedagogical and organisational issues.

This research does not address pedagogical approaches, diverse learner needs or learning styles, which can be explored in future studies.

The study described in this paper contributes to the body of system utilisation research by confirming an uneven pattern of VLS feature usage among educators in both institutions, whilst providing fresh insights into the limitations and challenges associated with the usage of two different VLSs, in two different universities. This research also highlights the significant differences in VLS usage patterns in the two different institutions and possible reasons for this disparity, which tentatively indicates that staff development and support seems to be an important aspect of VLS usage. In addition the findings suggests that differences in VLS usage can be attributed to teaching for distance education vs. teaching in a blended environment, as well as suitability of fit for different disciplines and for different academic levels of study. The finding that some VLS features are used more than others merits an investigation into the factors that influence the uptake and usage of VLS in higher education.

The quantitative findings indicate that the content cluster of VLS features are used more frequently by educators at both South African higher education institutions than the pedagogic, communication and management clusters, which has practical implications for educational technologists responsible for training interventions and staff development activities to promote the use of more interactive tools to support teaching and learning. The qualitative findings of this research categorises the challenges experienced with actual usage as system, user, pedagogic and organisational related, which in turn has practical implications for VLS designers, educational technologists and administrators in order to achieve more effective and optimal usage of VLSs. Further research is needed on how VLS design can be evolved to meet the diverse instructional methods of educators and learning styles of students, and the incorporation of personalised and adaptive learning into these platforms. This study also points to the need for additional research into analytics for VLSs and its uses in educational research.

\section{References}

Alexander, B. (2008). Deepening the chasm: Web 2.0, gaming, and course management systems. Journal of Online Learning and Teaching, 4(2), 198-204.

AuthorGEN. (n.d.). authorPOINT to create multimedia e-learning Flash presentations. Last accessed 4 Dec 2015. Retrieved from http://www.authorgen.com/authorpoint/index.htm

Bagarukayo, E. \& Kalema, B. (2015). Evaluation of elearning usage in South African universities: A critical review. International Journal of Education and Development using Information and Communication Technology (IJEDICT), 11(2), 168-183.

Beck, E. E. (2005). Learning management systems: The need for critical analyses. In Proceedings of the 4th Decennial Conference on Critical Computing: Between Sense and Sensibility (pp. 173-176). ACM. http://dx.doi.org/10.1145/1094562.1094592

Blackboard. (2006). Blackboard learning system designer and instructor reference. Blackboard, Inc. 
Blackboard. (n.d.). Elluminate Live! Last accessed 4 Dec 2015. Retrieved from http://www . elluminate.com/Services/Training/Elluminate_Live!/?id=418

Blinco, K., Mason, J., McLean, N. \& Wilson, S. (2004). Trends and issues in e-learning infrastructure development: A white paper for alt-i-lab. DEST (Australia) and JISC-CETIS (UK). Retrieved from http://www.researchgate.net/publication/237074439_Trends_Issues_in_eLearning_Infrastructure_Development

Branon, R. F. \& Essex, C. (2001). Synchronous and asynchronous communication tools in distance education. TechTrends, 45(1), 36-36. http://dx.doi.org/10.1007/BF02763377

Britain, S. \& Liber, O. (2004, February). A framework for the pedagogical evaluation of eLearning environments. Bolton Institute of Higher Education. Retrieved from http://www.researchgate.net/ publication/30502963_A_Framework_for_the_Pedagogical_Evaluation_of_Elearning_ Environments

Brown, C. \& Czerniewicz, L. (2008). Trends in student use of ICTs in higher education in South Africa. In Proceedings of the 10th Annual Conference of WWW Applications. Cape Town. 3-6 September 2008.

Brown, C. \& Czerniewicz, L. (2010). Debunking the 'digital native': Beyond digital apartheid, towards digital democracy. Journal of Computer Assisted Learning, 26(5), 357-369. http://dx.doi.org/ 10.1111/j.1365-2729.2010.00369.x

Brown, G. \& Peterson, N. (2008). The LMS mirror: School as we know IT versus school as we need IT and the triumph of the custodial class. MERLOT Journal of Online Learning and Teaching, 4(2), 190-7.

Cavus, N. \& Momani, A. M. (2009). Computer aided evaluation of learning management systems. Procedia-Social and Behavioral Sciences, 1(1), 426-430. http://dx.doi.org/10.1016/j. sbspro.2009.01.076

Cole, J. \& Foster, H. (2007). Using Moodle: Teaching with the popular open source course management system. O’Reilly. Retrieved from http://shop.oreilly.com/product/9780596529185.do

Czerniewicz, L. \& Brown, C. (2009). A study of the relationship between institutional policy, organisational culture and e-learning use in four South African universities. Computers \& Education, 53(1), 121-131. http://dx.doi.org/10.1016/j.compedu.2009.01.006

Dahlstrom, E., Walker, J. \& Dziuban, C. (2013). ECAR study of undergraduate students and information technology, 2013. EDUCAUSE Center for Analysis and Research. Retrieved from http://www.educause.edu/library/resources/ecar-study-undergraduate-studentsand-information-technology-2013

Dimdim. (n.d.). Dimdim web meeting download | Sourceforge.net. Last accessed 24 Sep 2012. Retrieved from http://sourceforge.net/projects/dimdim/

Facebook. (n.d.). Welcome to Facebook-Log in, sign up or learn more. Last accessed 4 Dec 2015.

Gallagher, S. (2003). The new landscape for course management systems. EDUCAUSE Center for Analysis and Research. Retrieved from http://www.educause.edu/library/resources/newlandscape-course-management-systems

Guest, G., MacQueen, K. M. \& Namey, E. E. (2011). Applied thematic analysis. Sage. 
Hurlburt, S. (2008). Defining tools for a new learning space: Writing and reading class blogs. MERLOT Journal of Online Learning and Teaching, 4(2), 182-189.

Jackson, C. (n.d.). University of KwaZulu-Natal Learning Management System (LMS) review. Retrieved from http://hdl.handle.net/10413/12608

Kemp, J. \& Livingstone, D. (2006). Putting a Second Life "metaverse" skin on learning management systems. In Proceedings of the Second Life education workshop at the Second Life community convention (Vol. 20). The University of Paisley CA, San Francisco.

Kompen, R. T., Edirisingha, P. \& Mobbs, R. (2010). Building Web 2.0-based personal learning environments: A conceptual framework. Presented at the EDEN Research Workshop 2008, Paris, 20th to 22nd October 2008. Retrieved from https://Ira.le.ac.uk/bitstream/2381/4398/ 1/EDEN\%20ResWksp\%202008\%20Torres\%20Kompen\%20et\%20al\%20Web\%202. 0\%20PLE\%20paper.pdf

Lang, L. \& Pirani, J. (2014). The learning management system evolution. EDUCAUSE Center for Analysis and Research. Retrieved from http://www.educause.edu/library/resources/learningmanagement-system-evolution

Meerts, J. (2003). Course management systems (CMS) EDUCAUSE Evolving Technologies Committee. Program for EDUCAUSE 2003. Retrieved from https://net.educause.edu/ir/library/pdf/ EDU0319a.pdf

Mendeley. (n.d.). Free reference manager and PDF organiser. Last accessed 7 Dec 2015. Retrieved from https://www.mendeley.com/

Mlitwa, N. (2007). e-Learning and learning management systems (LMS) in a changing higher education environment. In Proceedings of SACLA 2007: Transforming IS \& CS education and research in a changing Higher Education environment. Cape Town.

Mlitwa, N. \& Van Belle, J.-P. (2011). Mediators for lecturer perspectives on learning management systems at universities in the Western Cape, South Africa. In Proceedings of the Pacific Asia Conference on Information Systems (PACIS 2011), Brisbane (p. 135).

Monaghan, M. S., Cain, J. J., Malone, P. M., Chapman, T. A., Walters, R. W., Thompson, D. C. \& Riedl, S. T. (2011). Educational technology use among US colleges and schools of pharmacy. American Journal of Pharmaceutical Education, 75(5), Article 87. http://dx.doi.org/10.5688/ ajpe 75587

Morgan, G. (2003). Key findings: Faculty use of Course Management Systems. EDUCAUSE Center for Applied Research. Retrieved from https://www.educause.edu/ir/library/pdf/EKF/ekf0302. pdf

Mtebe, J. S. (2015). Learning Management System success: Increasing Learning Management System usage in higher education in sub-Saharan Africa. International Journal of Education and Development using Information and Communication Technology (IJEDICT), 11(2), 51-64.

Ng'ambi, D. \& Bozalek, V. (2013). Editorial: Emerging technologies and changing learning/teaching practices. British Journal of Educational Technology, 44(4), 531-535. http://dx.doi.org/10. $1111 /$ bjet. 12061

Oliver, K. (2001). Recommendations for student tools in online course management systems. Journal of Computing in Higher Education, 13(1), 47-70. http://dx.doi.org/10.1007/BF02940944 
Oliver, K. \& Moore, J. (2008). Faculty recommendations for web tools: Implications for course management systems. Journal of Computing in Higher Education, 19(2), 3-24. http://dx.doi. org/10.1007/BF03033424

Petter, S., DeLone, W. \& McLean, E. (2008). Measuring information systems success: Models, dimensions, measures, and interrelationships. European Journal of Information Systems, 17(3), 236-263. http://dx.doi.org/10.1057/ejis.2008.15

Phahlane, M. M. \& Kekwaletswe, R. M. (2012). Contextualized framework for ubiquitous learning support using a learning management system. International Journal of Computer and Information Technology (IJCIT), 1(2), 109-112.

QSR International. (n.d.). NVivo 10 research software for analysis and insight. Retrieved from http://www.qsrinternational.com/products_nvivo.aspx

Rohleder, P., Bozalek, V., Carolissen, R., Leibowitz, B. \& Swartz, L. (2008). Students' evaluations of the use of e-learning in a collaborative project between two South African universities. Higher Education, 56(1), 95-107. http://dx.doi.org/10.1007/s10734-007-9091-3

Sekaran, U. \& Bougie, R. (2010). Research methods for business: A skill building approach (5th edition). John Wiley \& Sons.

Siemens, G. (n.d.). Elearnspace everything elearning. Last accessed 09 Oct 2012. Retrieved from http://www.elearnspace.org/Articles/learning_communities.htm

Turnitin, L. (n.d.). Turnitin-Originality check, online grading \& peer review. Last accessed 24 Sep 2012. Retrieved from http://turnitin.com

Van der Valk, F. (2008). Identity, power, and representation in virtual environments. MERLOT Journal of Online Learning and Teaching, 4(2), 205-211.

Venkatesh, V., Brown, S. A. \& Bala, H. (2013). Bridging the qualitative-quantitative divide: Guidelines for conducting mixed methods research in information systems. MIS Quarterly, 37(1), 21-54.

Vovides, Y., Sanchez-Alonso, S., Mitropoulou, V. \& Nickmans, G. (2007). The use of e-learning course management systems to support learning strategies and to improve self-regulated learning. Educational Research Review, 2(1), 64-74. http://dx.doi.org/10.1016/j.edurev.2007.02. 004

Welle-Strand, A. \& Thune, T. (2003). E-learning policies, practices and challenges in two Norwegian organizations. Evaluation and Program Planning, 26(2), 185-192. http://dx.doi.org/10. 1016/S0149-7189(03)00006-5

WICHE Cooperative for Educational Technology. (n.d.). Edutools | WCET. Last accessed 08 Oct 2012. Retrieved from http://wcet.wiche.edu/learn/edutools

Yahoo, I. (n.d.). Flickr, a Yahoo company | Flickr_Photo sharing! Last accessed 4 Dec 2015.

Yueh, H.-P. \& Hsu, S. (2008). Designing a learning management system to support instruction. Communications of the ACM, 51 (4), 59-63. http://dx.doi.org/10.1145/1330311.1330324

Zotero. (n.d.). Zotero | Home. Last accessed 24 Sep 2012. Retrieved from http://www.zotero.org 